\title{
Differential item functioning of the SF-12 in a population-based regional joint replacement registry
}

Iraj Yadegari', Eric Bohm³ , Olawale F. Ayilara ${ }^{1,2}$, Lixia Zhang ${ }^{1,2}$, Richard Sawatzky ${ }^{4}$, Tolulope T. Sajobi ${ }^{5}$ and Lisa M. Lix ${ }^{1,2^{*}}$ (D)

\begin{abstract}
Background: Joint replacement, an increasingly common procedure amongst older adults, can substantially improve health-related quality of life (HRQoL). However, differential item functioning (DIF) may affect the accurate interpretation of differences in HRQoL amongst patients with different demographic and health status characteristics but the same underlying (i.e., latent) level of the investigated construct. This study tested for DIF in pre-operative SF-12 physical health $(\mathrm{PH})$ and mental health $(\mathrm{MH})$ sub-scale items amongst patients undergoing total hip arthroplasty (THA) and total knee arthroplasty (TKA).
\end{abstract}

Methods: Data were from a population-based joint replacement registry from the Canadian province of Manitoba. TKA and THA patients who had surgery between 2009 and 2015 and completed a pre-operative assessment were included. DIF was tested using the multiple indicators multiple causes (MIMIC) method with sex, age group, body weight status, and presence of multiple comorbid conditions (i.e., multimorbidity) as covariates. Analyses were stratified by joint type.

Results: The study cohort included 8820 patients; $42.1 \%$ underwent THA, 57.3\% were female, 32.7\% were $70+$ years, and $52.8 \%$ were obese. For each sub-scale, four of the six items exhibited DIF in both THA and TKA groups. Differences in the covariate effect estimates for DIF and No-DIF models on the MH latent variable were largest for age and body weight status for the THA group, and for sex and multimorbidity for the TKA group. All of the differences were small for PH. Multimorbidity had the strongest association with $\mathrm{PH}$ and age and sex had the strongest association with $\mathrm{MH}$ in the DIF models.

Conclusions: Demographic and health status characteristics influenced SF-12 PH and MH item responses in joint replacement populations, although the size of the effects were not large for $\mathrm{PH}$. We recommend testing and adjusting for DIF effects to ensure comparability of HRQOL measures in joint replacement populations.

Keywords: Arthroplasty, Clinical registry, Health-related quality of life, Measurement bias

\section{Background}

Joint replacement is an increasingly common procedure; rates of total hip and knee arthroplasty (THA/TKA) are increasing worldwide $[1,2]$. THA and TKA can positively impact the health-related quality of life (HRQoL) of patients, resulting in substantial improvements in functional abilities and reductions in pain [3, 4]. There is strong interest

\footnotetext{
*Correspondence: lisa.lix@umanitoba.ca

'Department of Mathematics and Statistics, University of Ottawa, Ottawa, ON, Canada

${ }^{2}$ Department of Community Health Sciences, University of Manitoba,

S113-750 Bannatyne Avenue, Winnipeg, MB R3E OW3, Canada

Full list of author information is available at the end of the article
}

worldwide in the incorporation of patient-reported outcome measures (PROMs) into joint replacement registries for monitoring appropriateness of care, improvements in health status, and health system performance [5]. The International Society of Arthroplasty Registries has convened working groups to evaluate and advise on best practices in the selection, administration, and interpretation of PROMs for joint replacement registries [6, 7].

Measurement validity and reliability are key considerations in the interpretation of patient responses on PROMs. An important validity criterion relevant to group comparisons is that the scoring of PROMs must be free

(c) The Author(s). 2019 Open Access This article is distributed under the terms of the Creative Commons Attribution 4.0 International License (http://creativecommons.org/licenses/by/4.0/), which permits unrestricted use, distribution, and reproduction in any medium, provided you give appropriate credit to the original author(s) and the source, provide a link to the Creative Commons license, and indicate if changes were made. The Creative Commons Public Domain Dedication waiver (http://creativecommons.org/publicdomain/zero/1.0/) applies to the data made available in this article, unless otherwise stated. 
from the effects of differential item functioning (DIF), which arises when patients with the same underlying level of the latent trait that the PROM is intended to measure do not interpret a PROM's items in the same way [8]. DIF results in different item response probabilities for individuals with similar observed characteristics [9]. If DIF is present, then observed group differences will at least partially reflect something other than the latent construct, such as different interpretations of the item(s). DIF can result in biased between-group comparisons because the response patterns may reflect attributes other than those that the instrument is intended to measure.

Brief general-purpose PROMs, such as the 12-item Short Form Survey (i.e., SF-12), are advantageous to administer to joint replacement patients because they facilitate comparisons across patient populations while reducing participant response burden at pre- and postoperative measurement occasions. The SF-12 has undergone comprehensive psychometric evaluations of its reliability and validity [10].

Although DIF has been tested in other measurement instruments $[9,11-13]$, only a few studies have investigated DIF for the SF-12. DIF has been detected for the SF-12 in population-based data [14, 15]; a study in the general population revealed DIF effects by age, sex, and level of education [14]. However, DIF has not been thoroughly investigated in specific populations, such as in joint replacement populations.

The goal of our study was to test for DIF on the SF-12 physical health $(\mathrm{PH})$ and mental health $(\mathrm{MH})$ sub-scale items in a joint replacement population. We considered demographic characteristics in addition to health status characteristics in assessing DIF; the latter have recently been examined as potential contributors to DIF in PROMs for patients with osteoarthritis [16] and joint pain [17].

\section{Methods}

\section{Data source}

Data were from the Winnipeg Regional Health Authority Joint Replacement Registry; the Health Authority is the largest health region in the province of Manitoba, Canada and has a population of more than 700,000 residents. The province has a single-payer health care system that provides necessary hospital, medical and surgical services to all individuals eligible to receive health services. The Registry captures more than $90 \%$ of the joint replacement procedures conducted within the health region and more than three-quarters of all procedures in the entire province.

The Registry was initiated in 2004 with partial capture of information on all joint replacement surgeries; this was expanded to full mandatory capture of information in 2005. The Registry has been described in detail elsewhere [18]; it contains patient demographics, comorbid conditions, surgical technique, implant details, and complications. Both general and condition-specific HRQoL measures are included in the Registry. The former includes the SF-12 and the latter includes the Oxford Hip and Knee scores [19, 20]. Pre-operative data capture occurs in the pre-admission clinic under the guidance of a clinic nurse. Post-operative data are collected via a mailout questionnaire conducted by Registry staff. Data entry is undertaken by the hospital medical records department for hospital stay characteristics and by Registry staff for PROMs. All data are collected via standardized instruments and the process of data collection and entry is overseen by Registry staff for all hospital sites.

The study cohort included all individuals who underwent THA or TKA between April 1, 2009, and March 31, 2015 and for whom complete pre-operative data were available. All patients from one hospital were excluded in 2011 because pre-operative questionnaires were not distributed that year.

\section{Measures}

The SF-12 (version 2) is a general-purpose instrument consisting of 12 items that comprise eight sub-domains [21]: physical functioning, role physical, bodily pain, general health, vitality, social functioning, role-emotional, and mental health. The eight sub-domain scores can be weighted and summarized into $\mathrm{MH}$ and $\mathrm{PH}$ sub-scale scores. According to this model, the items from the physical functioning, role-physical, bodily pain, and general health sub-domains are indicators of $\mathrm{PH}$ while vitality, social functioning, role-emotional, and mental health items are indicators for $\mathrm{MH}$. Assessments of construct validity using latent variable models has confirmed this measurement structure [21,22], although correlations of residual errors for items associated with $\mathrm{PH}$ and $\mathrm{MH}$ latent variables has been observed [21-23].

Covariates used to describe the study cohort and examine potential DIF sources for the SF-12 included sex, age group, body weight status, and multimorbidity, the presence of two or more chronic conditions [24]. Age was classified as 60 years or less (reference category), 61 to 70 years, and greater than 70 years; the dummy variables AGE1 (0 if age $\leq 60$ and 1 otherwise) and AGE2 ( 0 if age $\leq 70$ and 1 otherwise) were created to represent these age categories. Body weight status was based on body mass index (BMI), which was calculated from measured height and weight $\left(\mathrm{kg} / \mathrm{m}^{2}\right)$ captured by clinic nurses; it was categorized as underweight or normal weight (BMI $\leq 25.0$; reference category), overweight $(25.0<\mathrm{BMI} \leq 30.0)$, and obese $(\mathrm{BMI}>30.0)[25,26]$. The dummy variables of BMI1 (0 if BMI $\leq 25.0$ and 1 otherwise) and BMI2 (0 if BMI $\leq 30.0$ and 1 otherwise) were created to represent these categories. 
Information about 14 chronic conditions was captured from a self-report questionnaire administered by clinic staff at the pre-operative occasion; individuals were classified as having multimorbidity if they had at least two of these chronic conditions. A single dummy variable COMORB $(1=$ presence of $2+$ comorbid conditions and 0 otherwise) was defined.

\section{Statistical analysis}

The analyses were conducted for patients with complete information (i.e., no missing data) on all SF-12 items. Descriptive analyses were conducted using frequencies and percentages. All analyses were stratified by joint type.

A variety of methods have been used to detect DIF including logistic regression [27], item response theory (IRT) models $[28,29]$, and the multiple indicators multiple causes (MIMIC) model [30-32]. IRT and MIMIC models can be applied to binary and ordinal item responses, and are flexible to incorporate one or more latent constructs. In addition, the MIMIC is flexible to allow for the specification of dependencies between item residuals [23, 33]. Consequently, we adopted the MIMIC model to test for uniform DIF.

We constructed baseline models for $\mathrm{MH}$ and $\mathrm{PH}$ subscales based on the hypothesized measurement structure of the SF-12, in which the $\mathrm{PH}$ and $\mathrm{MH}$ items have no cross loading items (Additional file 1: Figures S1 and S2) . The baseline models included two correlated residuals (items P2 and P3, P4 and P5) for the PH sub-scale and two correlated residuals (items M1 and M2, M3 and M5) for the MH sub-scale $[21,23]$ and confirmed by the assessment of fit measures, which demonstrated poorer overall fit when these residuals were not correlated.

In a MIMIC model with $m$ items and $k$ covariates, the latent response for the $i$ th item $(i=1, \ldots, m)$ is regressed on the latent variable $F$ and the covariate vector $\mathbf{Z}$,

$$
y_{i}^{*}={ }_{i} F+\boldsymbol{\beta}_{i}^{\prime} \mathbf{Z}+{ }_{i},
$$

where $\varepsilon_{i}$ is the error term, $\lambda_{i}$ is the factor loading, and $\boldsymbol{\beta}_{i}^{\prime}=\left({ }_{i 1} \cdots i k\right)$ is the vector of the effects of covariates on the latent response $y_{i}^{*}$. The latent response is scored via a threshold model

$$
y_{i}=c, \text { if } \tau_{i(c)}<y_{i}^{*} \leq \tau_{i(c+1)},
$$

for categories $c=0,1,2, \ldots, C-1$, where $\boldsymbol{\tau}_{i(\mathbf{0})}=-\infty$ and $\boldsymbol{\tau}_{\boldsymbol{i}(\boldsymbol{C})}=+\infty$. Thus, $y_{i}$ is a polytomous variable which takes discrete values $0,1, \ldots, C-1$. In addition, the latent factor is regressed on the covariates via

$$
F=' \mathbf{Z}+\eta,
$$

where $\eta$ is the error term and is independent of $\mathbf{Z}$, and $\gamma^{\prime}=\left(\gamma_{1}, \ldots, \gamma_{k}\right)$ is a vector of regression coefficients that describe between group differences in $F$ (Fig. 1). These formulations enable us to estimate and test $\boldsymbol{\beta}_{i}^{\prime}$ conditional on $F$. If $\boldsymbol{\beta}_{i}^{\prime} \neq \mathbf{0}$, there is a significant direct effect from the covariates to the latent response $y_{i}^{*}$ which means that DIF exists in the $i$ th item $[34,35]$.

There were four primary steps in the DIF analysis. First, unidimensionality of the measurement scales was assessed. Next, anchor items were selected. Then, each item was assessed for DIF. Finally after adjustment for DIF, the contributions of the covariates and items to the final DIF model was assessed.

In the first step the unidimensionality assumption, which implies that all sub-scale items measure a single latent construct, was examined by applying a single-factor model with an oblique rotation to the polychoric correlation matrix for the items for each of the $\mathrm{MH}$ and $\mathrm{PH}$ sub-scales. To make a decision about unidimensionality, we used two criteria: (a) the existence of only one eigenvalue greater than one, and (b) a large value for the ratio of the first to second eigenvalues (i.e., $r>4$ ) [36]. We used several criteria to evaluate the goodness-of-fit of a singlefactor model. We considered the model to be a reasonable fit to the data if it had a small root mean square error of approximation (i.e., RMSEA < 0.06), a large comparative fit index (i.e., CFI > 0.95), a large Tucker-Lewis Index (i.e., TLI $>0.95$ ), and a small weighted root mean square residual (i.e., WRMR < 1.0) [37-39].

In the second step, we selected anchor items (i.e., DIFfree items). At least one anchor item must be selected to define the latent construct on which the groups are compared. We used the following method to select the anchor item(s). First, for each sub-scale, a single-factor model was fit to the data; it included direct effects of the covariates on the latent variable but no direct effects between the covariates and the sub-scale items. This was the base model. Next, a series of single-factor models were fit to the data that added direct effects from the covariates; there was one model for each sub-scale item. A

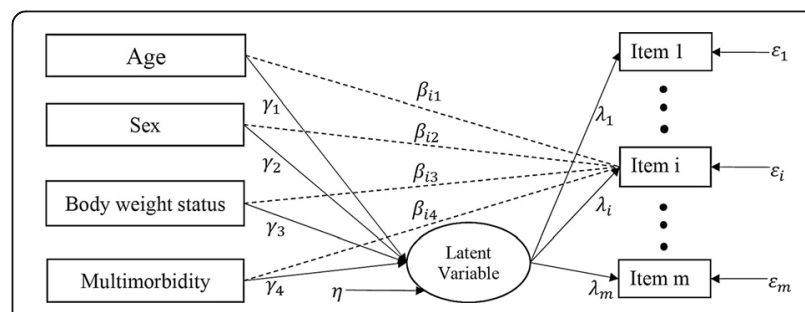

Fig. 1 Example of MIMIC model permitting DIF for the ith item. The dashed arrow from each covariate to the ith item represents the direct effect; $\gamma_{k}=$ regression coefficient for the effect of the $k$ th covariate on the latent variable; $\lambda_{i}=$ the regression coefficient for the latent variable and the $i$ th item; $\beta_{i k}=$ regression coefficient showing the effect of the $k$ th covariate on the ith item; $\varepsilon_{i}=$ measurement error for the ith item; $\eta=$ residual for the latent variable 
$\chi^{2}$ difference test was used to compare the models with and without the direct effects. The item(s) with the smallest $\chi^{2}$ statistics was(were) selected as the anchor item(s) [40]. Note that this process was applied to the data for all cohort members so that the same anchor items were selected for both THA and TKA patients. This facilitated the interpretation of the study findings because the same item(s) served as reference points for all analyses. We confirmed the same anchor items in separate analyses for THA and TKA patients.

In the third step, item purification was conducted to identify the items affected by DIF. First, a full model was fit to the data that included direct effects from covariates to all sub-scale items except the anchor item(s). Next, we fit a series of reduced models that excluded direct effects from the covariates to each item; this was done one item at a time. A $\chi^{2}$ difference test was used to compare these nested models using DIFFTEST for the robust weighted least square estimation method (i.e., WLSMV) in Mplus (https://www.statmodel.com/chidiff.shtml). A large $\chi^{2}$ difference statistic implies uniform DIF is present for the item.

The fourth step was to fit a model that included direct effects from the covariates to all DIF items (i.e., the items for which DIF was identified in the previous step) and direct effects of the covariates on the latent variable $[9,31]$. This model was used to obtain parameter estimates of direct effects of the covariates on the $\mathrm{PH}$ and $\mathrm{MH}$ sub-scale items. The total effect of DIF was measured via the relative difference between standardized coefficient estimates for the DIF and No-DIF models (i.e., difference in standardized estimates divided by the standardized estimates for the No-DIF model). A difference in standardized coefficients of 0.20 was considered as small, 0.50 as moderate, and 0.80 or greater as large [41]. Estimates of the total effects (i.e., direct and indirect effects) of the covariates on the individual sub-scale items were also produced.

We used an approach based on dominance analysis [42] and Nagelkerke's coefficient of determination [43-45] to assess the relative importance of both individual items and covariates in the DIF models. Specifically, an item's importance in the final DIF model was estimated based on its contribution (i.e., direct effects from the covariates to the item) conditional on the contributions of the other items. To measure the item's importance, a full model was fit to the data that include direct effects of the covariates on all DIF items identified in the previous step, as well as direct effects of the covariates on the latent variable. Next, we fit a series of reduced models that excluded direct effects from the covariates to each DIF item; we did this one item at a time. The importance of each DIF item was assessed using an adaptation of Nagelkerke's coefficient of determination,

$$
R^{2}=\left(1-e^{-\left(\Delta X^{2}\right) / N}\right) /\left(1-e^{-\chi_{R}^{2} / N}\right)
$$

where $N$ is the total sample size, $\chi_{R}^{2}$ is the chi-square test statistic for the reduced model, and $\Delta \chi^{2}$ is the scaled difference in $X^{2}$ test statistics for the reduced and full models. The statistic $R^{2}$ is equal to Nagelkerke's coefficient of determination if we replace $X_{R}^{2}$ with $-2 \log \left(L_{R}\right)$ and $\Delta \chi^{2}$ with $-2 \log \left(L_{R} / L_{F}\right)$ in maximum likelihood estimation, where $L_{R}$ and $L_{F}$ are the likelihood of the reduced and full models, respectively. An item was more important than all other items if it had the largest $R^{2}$ amongst all items.

The importance of a covariate in the final DIF model was measured by its contribution (i.e., direct effects from the covariate to all DIF items), conditional on the contribution of the other model covariates. We used a similar approach to that described above to measure covariate importance in the final DIF model. First, a full model was fit to the data that include direct effects from all covariates to the DIF items, as well as direct effects of the covariates on the latent variable. Next, a series of reduced models were fit to the data that excluded the effect of each covariate; this was done one covariate at a time. Using the adapted Nagelkerke coefficient of determination, we measured the importance of each covariate. A covariate was more important than all other covariates if it had the largest $R^{2}$ amongst all of the covariates.

All analyses were conducted using Mplus software, version 8 . In all analyses, the latent factor mean was constrained to zero and its variance was fixed to one.

\section{Results}

The study cohort included 8820 patients with complete information on all SF-12 items at the pre-operative occasion. Overall, $42.1 \%$ patients had THA in the observation period.

For the THA group (Table 1), 53.4\% were female, onethird $(33.7 \%)$ were 60 years of age or younger, and onethird (33.6\%) were more than 70 years of age. Overweight and obese individuals accounted for $37.9 \%$ and $41.8 \%$ of the THA group, respectively. Slightly more than one-half of THA patients had multimorbidity. The most common chronic conditions were hypertension, other (i.e., secondary) osteoarthritis, and back pain.

For the TKA group, $60.2 \%$ were female and approximately one-third $(30.0 \%)$ were 60 years of age or younger and one-third $(32.0 \%)$ were more than 70 years of age. Overweight and obese individuals accounted for $28.7 \%$ and $60.8 \%$ of patients, respectively. Multimorbidity was identified in almost two-thirds of TKA patients (62.2\%) 
Table 1 Frequency (\%) of demographic and health status characteristics of study cohort, stratified by type of joint replacement

\begin{tabular}{|c|c|c|c|}
\hline Characteristic & $\begin{array}{l}\text { THA } \\
n(\%)\end{array}$ & $\begin{array}{l}\text { TKA } \\
n(\%)\end{array}$ & $\begin{array}{l}\text { Overall } \\
n(\%)\end{array}$ \\
\hline Total & $3714(42.1)$ & $5106(57.9)$ & $8820(100.0)$ \\
\hline \multicolumn{4}{|l|}{ Sex } \\
\hline Female & $1982(53.4)$ & $3074(60.2)$ & $5056(57.3)$ \\
\hline Male & $1732(46.6)$ & $2032(39.8)$ & $3764(42.7)$ \\
\hline \multicolumn{4}{|l|}{ Age } \\
\hline$\leq 60$ years & $1253(33.7)$ & $1534(30.0)$ & $2787(31.6)$ \\
\hline $61-70$ years & $1214(32.6)$ & $1938(38.0)$ & $3152(35.7)$ \\
\hline$>70$ years & $1247(33.6)$ & $1634(32.0)$ & $2881(32.7)$ \\
\hline \multicolumn{4}{|l|}{ Body Weight Status } \\
\hline Under weight or normal weight $(\mathrm{BMI}<=25.0)$ & $755(20.3)$ & $533(10.4)$ & $1288(14.6)$ \\
\hline Overweight (BMI = 25.1-29.9) & $1406(37.9)$ & $1466(28.7)$ & $2872(32.6)$ \\
\hline Obese $(\mathrm{BMI}=30.0+)$ & $1553(41.8)$ & $3107(60.8)$ & $4660(52.8)$ \\
\hline \multicolumn{4}{|l|}{ Multimorbidity } \\
\hline $2+$ Chronic conditions & $1986(53.5)$ & $3174(62.2)$ & $5160(58.5)$ \\
\hline$<2$ Chronic conditions & $1728(46.5)$ & $1932(37.8)$ & $3660(41.5)$ \\
\hline \multicolumn{4}{|l|}{ Chronic Conditions } \\
\hline Hypertension & $1639(44.1)$ & $2725(53.4)$ & $4364(49.5)$ \\
\hline Other osteoarthritis & $1476(39.7)$ & $2272(44.5)$ & $3748(42.5)$ \\
\hline Back pain & $1450(39.0)$ & $1914(37.5)$ & $3364(38.1)$ \\
\hline Diabetes & $417(11.2)$ & $913(17.9)$ & $1330(15.1)$ \\
\hline Heart disease & $385(10.4)$ & $559(10.9)$ & $944(10.7)$ \\
\hline Depression & 395 (10.6) & 705 (13.8) & $1100(12.5)$ \\
\hline Rheumatoid arthritis & $294(7.9)$ & $585(11.5)$ & $879(10.0)$ \\
\hline Stomach ulcer & $168(4.5)$ & $337(6.6)$ & $505(5.7)$ \\
\hline Cancer & $183(4.9)$ & $234(4.6)$ & $417(4.7)$ \\
\hline Anemia & $153(4.1)$ & $228(4.5)$ & $381(4.3)$ \\
\hline Lung disease & $165(4.4)$ & $263(5.2)$ & $428(4.9)$ \\
\hline Kidney disease & $72(1.9)$ & $104(2.0)$ & $176(2.0)$ \\
\hline Liver disease & $36(1.0)$ & $58(1.1)$ & $94(1.1)$ \\
\hline Other condition & $741(20.0)$ & $1165(22.8)$ & $1906(21.6)$ \\
\hline
\end{tabular}

THA Total hip arthroplasty, TKA Total knee arthroplasty, BMI Body mass index

and the most common chronic conditions were the same as for the THA group.

The frequencies of responses to the $\mathrm{MH}$ and $\mathrm{PH}$ subscale items are reported in Table 2 for the entire cohort. For the MH sub-scale, close to half (46.4\%) of patients responded "A little of the time" to M3 ("felt calm and peaceful"), while $36.0 \%$ of patients responded "None of the time" to M2 ("less careful than usual"). Furthermore, for the PH sub-scale, more than half (58.9\%) of patients respond "Yes, limited a lot" to P2 ("moderate activities") while $74.4 \%$ of patients respond "Yes, limited a lot" to P3 ("climbing several flights of stairs").

With respect to multimorbidity, $19.0 \%$ of individuals in the cohort had no chronic conditions and $22.5 \%$ had a single chronic condition. Almost one-quarter (24.2\%) had two chronic conditions, and the remainder had three or more chronic conditions.

Exploratory factor analysis revealed that for both the $\mathrm{PH}$ and $\mathrm{MH}$ sub-scales there existed only one eigenvalue with a value greater than one. The ratio of the first to second eigenvalues was larger than four, except for the PH sub-scale in the TKA group where it was only slightly less than this criterion $(r=3.95)$. In addition, the second eigenvalue was similar in size to the third eigenvalue in both groups and for both sub-scales. Therefore, it was reasonable to accept unidimensionality of the $\mathrm{MH}$ and $\mathrm{PH}$ sub-scales for both the THA and TKA groups. 
Table 2 Frequencies (\%) of responses to the SF-12 mental health (MH) and physical health (PH) sub-scale items

\begin{tabular}{|c|c|c|c|c|c|}
\hline \multicolumn{6}{|l|}{ MH Sub-scale } \\
\hline & All of the time & Most of the time & Some of the time & A little of the time & None of the time \\
\hline M1: Accomplished less than would like & $634(7.2)$ & $1324(15.0)$ & $2108(23.9)$ & $1858(21.1)$ & $2896(32.8)$ \\
\hline M2: Less careful than usual & $564(6.4)$ & $1240(14.1)$ & $1998(22.7)$ & $1841(20.9)$ & $3177(36.0)$ \\
\hline M3: Felt calm and peaceful & $373(4.2)$ & $1227(13.9)$ & $2510(28.5)$ & $4094(46.4)$ & $616(7.0)$ \\
\hline M4: Have a lot of energy & $1017(11.5)$ & $2401(27.2)$ & $3150(35.7)$ & $2027(23.0)$ & $225(2.6)$ \\
\hline \multirow[t]{2}{*}{ M5: Felt downhearted and depressed } & $165(1.9)$ & $595(6.7)$ & $2254(25.6)$ & $2860(32.4)$ & $2946(33.4)$ \\
\hline & Not at all & A little bit & Moderately & Quite a bit & Extremely \\
\hline M6: Have social limitations & $556(6.3)$ & $1352(15.3)$ & $2545(28.9)$ & $1915(21.7)$ & $2452(27.8)$ \\
\hline \multicolumn{6}{|l|}{ PH Sub-scale } \\
\hline & Excellent & Very good & Good & Fair & Poor \\
\hline \multirow[t]{2}{*}{ P1: General health } & $150(1.7)$ & $1021(11.6)$ & $4181(47.4)$ & $2892(32.8)$ & $576(6.5)$ \\
\hline & Yes, limited a lot & Yes, limited a little & No, not limited at all & & \\
\hline P2: Limits in moderate activity & $5198(58.9)$ & $3031(34.4)$ & $591(6.7)$ & & \\
\hline \multirow[t]{2}{*}{ P3: Climbing several flights of stairs } & $6563(74.4)$ & $1910(21.7)$ & $347(3.9)$ & & \\
\hline & All of the time & Most of the time & Some of the time & A little of the time & None of the time \\
\hline P4: Accomplished less than would like & $2564(29.1)$ & $3199(36.3)$ & $2049(23.2)$ & $731(8.3)$ & $277(3.1)$ \\
\hline P5: Limited in work and activity & $2680(30.4)$ & $3291(37.3)$ & 1989 (22.6) & $633(7.2)$ & $227(2.6)$ \\
\hline P6: Have pain with normal work & $1825(20.7)$ & $3942(44.7)$ & $2118(24.0)$ & $804(9.1)$ & $131(1.5)$ \\
\hline
\end{tabular}

In the baseline model for the $\mathrm{PH}$ and $\mathrm{MH}$ sub-scales, two correlated residuals for the $\mathrm{PH}$ sub-scale (items P2 and P3, P4 and P5) and four correlated residuals for the MH sub-scale (items M1 and M2, M3 and M5) were considered for inclusion based on the empirical results and previous research [21, 23]. Adding residual correlations for these items resulted in an acceptable model fit (Table 3) . Specifically, the single-factor model fit to the MH subscale items for the THA group had RMSEA $=0.05, \mathrm{CFI}=$
1.00, $\mathrm{TLI}=1.00$, and $\mathrm{WRMR}=0.62$ and for the TKA group it had RMSEA $=0.03, \mathrm{CFI}=1.00$, TLI $=1.00$, and WRMR $=0.38$ for the TKA group. The single-factor model fit to the PH sub-scale items had RMSEA $=0.03$, $\mathrm{CFI}=1.00, \mathrm{TLI}=1.00$, and $\mathrm{WRMR}=0.61$ for the THA group. For the TKA group, this model had RMSEA $=0.02$, $\mathrm{CFI}=1.00, \mathrm{TLI}=1.00$, and $\mathrm{WRMR}=0.52$.

We selected anchor items empirically for each subscale. We selected items M5 ("Felt downhearted and

Table 3 Goodness-of-fit statistics for the SF-12 mental health (MH) and physical health (PH) sub-scales with and without correlated residual variances, stratified by type of joint replacement

\begin{tabular}{|c|c|c|c|c|c|}
\hline Model & Joint Type & RMSEA $(90 \% \mathrm{Cl})$ & $\mathrm{CFI}$ & TLI & WRMR \\
\hline \multicolumn{6}{|l|}{ MH Sub-scale } \\
\hline \multirow[t]{2}{*}{ No residual variance correlations } & THA & $0.22(0.21,0.23)$ & 0.97 & 0.94 & 4.77 \\
\hline & TKA & $0.21(0.21,0.22)$ & 0.97 & 0.95 & 5.18 \\
\hline \multirow[t]{2}{*}{ With residual variance correlations: items $\mathrm{M} 1$ and $\mathrm{M} 2, \mathrm{M} 3$ and $\mathrm{M} 5$} & THA & $0.15(0.14,0.15)$ & 0.99 & 0.97 & 2.47 \\
\hline & TKA & $0.14(0.13,0.15)$ & 0.99 & 0.98 & 2.76 \\
\hline \multirow[t]{2}{*}{ With residual variance correlations: items $\mathrm{M} 1$ and $\mathrm{M} 2, \mathrm{M} 3$ and $\mathrm{M} 5, \mathrm{M} 3$ and $\mathrm{M} 4, \mathrm{M} 4$ and $\mathrm{M} 6$} & THA & $0.05(0.04,0.07)$ & 1.00 & 1.00 & 0.62 \\
\hline & TKA & $0.03(0.02,0.04)$ & 1.00 & 1.00 & 0.38 \\
\hline \multicolumn{6}{|l|}{ PH Sub-scale } \\
\hline \multirow[t]{2}{*}{ No residual variance correlations } & THA & $0.19(0.18,0.20)$ & 0.98 & 0.97 & 4.49 \\
\hline & TKA & $0.15(0.14,0.15)$ & 0.98 & 0.97 & 3.95 \\
\hline \multirow[t]{2}{*}{ With residual correlations: items P2 and P3, P4 and P5 } & THA & $0.03(0.02,0.04)$ & 1.00 & 1.00 & 0.61 \\
\hline & TKA & $0.02(0.01,0.03)$ & 1.00 & 1.00 & 0.52 \\
\hline
\end{tabular}

THA Total hip arthroplasty, TKA Total knee arthroplasty, RMSEA Root mean square error of approximation, CFI Comparative fit index, TLI Tucker-Lewis index, WRMR Weighted root mean square residual, $C l$ Confidence interval; values in boldface font represent the fit statistics for the best-fitting models 
depressed") and M6 ("Social limitations") for the MH sub-scale and items P2 ("Moderate activity") and P6 ("Have pain with normal work)" for the $\mathrm{PH}$ sub-scale, because they had the smallest $\chi^{2}$ statistics. Specifically, the $\chi^{2}$ statistics had values of $96.9,157.1,150.9,160.1$, 17.7, and 26.4 for items M1 to M6, respectively and values of 719.6, 41.0, 136.9, 62.2, 99.2, and 43.5 for items P1 to P6, respectively. .

Then we tested all non-anchor items for uniform DIF. For the MH sub-scale, all of the $\chi^{2}$ difference tests produced statistically significant results for both the TKA and THA groups, suggesting uniform DIF was present in all non-anchor items (see Table 4). Furthermore, the $X^{2}$ difference tests suggested the presence of uniform DIF in all non-anchor items for the $\mathrm{PH}$ sub-scale for both the THA and TKA groups.

Table 5 provides estimates of the direct effects of the covariates on the latent variables. As well, differences in the estimates when there were direct effects from the covariates to the items (i.e., DIF model) versus the case when there were no direct effects from covariates to the items (i.e., No-DIF model) are provided. As Table 5 reveals, in both the THA and TKA groups, the PH and $\mathrm{MH}$ latent variables were always negatively associated with the covariates COMORB and BMI2 and positively associated with sex. This indicates that patients with multimorbidity had smaller $\mathrm{PH}$ and $\mathrm{MH}$ latent variable scores on average, relative to other patients; obese patients had smaller $\mathrm{PH}$ and $\mathrm{MH}$ latent variable scores

Table 4 Tests for differential item functioning on the SF-12 mental health $(\mathrm{MH})$ and physical health $(\mathrm{PH})$ sub-scale items, stratified by type of joint replacement

\begin{tabular}{|c|c|c|c|c|c|c|}
\hline \multirow[t]{2}{*}{ Item } & \multicolumn{3}{|l|}{ THA } & \multicolumn{3}{|l|}{ TKA } \\
\hline & $\Delta x^{2}$ & $d f$ & $p$-value & $\Delta \times 2$ & $d f$ & $p$-value \\
\hline \multicolumn{7}{|c|}{ MH Sub-scale } \\
\hline M1 & 20.09 & 6 & 0.003 & 37.03 & 6 & $<0.001$ \\
\hline M2 & 31.85 & 6 & $<0.001$ & 73.22 & 6 & $<0.001$ \\
\hline M3 & 38.30 & 6 & $<0.001$ & 44.61 & 6 & $<0.001$ \\
\hline M4 & 99.26 & 6 & $<0.001$ & 83.93 & 6 & $<0.001$ \\
\hline M5 & * & * & * & * & * & * \\
\hline M6 & * & * & * & * & * & * \\
\hline \multicolumn{7}{|c|}{ PH Sub-scale } \\
\hline P1 & 244.32 & 6 & $<0.001$ & 425.16 & 6 & $<0.001$ \\
\hline P2 & * & * & * & * & $*$ & * \\
\hline P3 & 27.97 & 6 & $<0.001$ & 53.76 & 6 & $<0.001$ \\
\hline P4 & 12.96 & 6 & 0.044 & 16.34 & 6 & 0.012 \\
\hline P5 & 19.78 & 6 & 0.003 & 20.25 & 6 & 0.003 \\
\hline P6 & * & * & * & * & * & * \\
\hline
\end{tabular}

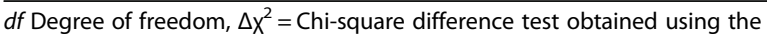
DIFFTEST procedure for WLSMV in MPlus; ${ }^{*}=$ anchor item; All tests are statistically significant at $a=0.05$ relative to non-obese patients, and the $\mathrm{PH}$ and $\mathrm{MH}$ latent variable scores for men were always larger than those for women. Almost all of the estimates were statistically significant in both the DIF and No-DIF models. The relative differences revealed that the largest effects of the covariates on the $\mathrm{MH}$ latent variable were observed for the age and body weight status covariates in the THA group. The majority of the standardized differences indicate small effects; the exceptions were for the covariates AGE2 and BMI1 for the THA group, which were moderate in size. For the PH latent variable, all of the covariates had smaller relative difference statistics than for the MH latent variable in both the TKA and THA groups.

Adjustment for DIF resulted in changes in the estimates of the total effects for most of the SF-12 MH and PH sub-scale items (Additional file 2: Tables S1 and S2). For the MH sub-scale items, in general the largest relative differences in total effect estimates for the DIF and no-DIF models were associated with the age and body weight status covariates; these differences were generally larger in size for the THA group than for the TKA group. For the $\mathrm{PH}$ sub-scale items, the relative differences in total effect estimates for the DIF and no-DIF models were all small, except for item P1 ("General health") in the THA group.

In the final DIF model for the PH sub-scale, multimorbidity and age had the largest and smallest relative importance, respectively as judged by the modified coefficient of determination (Fig. 2). This finding was consistent for both the THA and TKA groups. In the final DIF model for the MH sub-scale, sex and age had the largest importance for the THA group while multimorbidity and age had the largest $R^{2}$ statistics for the TKA group.

Finally, the relative importance analyses were conducted for all sub-scale items (Fig. 3). For the PH subscale, item P1 ("General health") had the largest contribution to the final DIF model while item P4 ("Accomplished less, physical") had the smallest contribution. For the MH sub-scale, item M4 ("Have a lot of energy") for the THA group and items M4 and M2 ("Less careful than usual") for the TKA group had the largest contributions to the final DIF model.

\section{Discussion}

This study tested for DIF in the PH and MH sub-scale items of the SF-12 across demographic and health status characteristics for patients having joint replacement surgery. We focused on responses given prior to surgery, as this is when health status measures (i.e., body weight status and presence of comorbid conditions) were collected, and also because pre-surgery assessments are an essential reference point for assessing the magnitude of 
Table 5 Regression model estimates for covariate associations with SF-12 mental health $(\mathrm{MH})$ and physical health $(\mathrm{PH})$ latent variable scores

\begin{tabular}{|c|c|c|c|c|c|c|c|c|c|c|}
\hline \multirow[t]{3}{*}{ Covariate } & \multicolumn{5}{|c|}{ MH Latent Variable } & \multicolumn{5}{|c|}{ PH Latent Variable } \\
\hline & \multicolumn{2}{|c|}{ No-DIF Model } & \multicolumn{2}{|c|}{ DIF Model } & \multirow[t]{2}{*}{$d$} & \multicolumn{2}{|c|}{ No-DIF Model } & \multicolumn{2}{|c|}{ DIF Model } & \multirow[t]{2}{*}{$d$} \\
\hline & $\overline{\text { Est }}$ & SE & $\overline{\text { Est }}$ & SE & & $\overline{\text { Est }}$ & SE & $\overline{\text { Est }}$ & SE & \\
\hline \multicolumn{11}{|l|}{ THA } \\
\hline AGE1 & 0.17 & 0.05 & 0.21 & 0.05 & 0.10 & 0.08 & 0.05 & 0.08 & 0.05 & 0.00 \\
\hline AGE2 & 0.08 & 0.05 & 0.13 & 0.05 & 0.50 & -0.12 & 0.05 & -0.14 & 0.05 & 0.11 \\
\hline BMI1 & 0.07 & 0.05 & 0.11 & 0.06 & 0.43 & -0.06 & 0.05 & -0.06 & 0.05 & -0.07 \\
\hline BMI2 & -0.20 & 0.04 & -0.21 & 0.05 & -0.03 & -0.25 & 0.04 & -0.20 & 0.04 & -0.20 \\
\hline SEX & 0.32 & 0.04 & 0.28 & 0.04 & -0.21 & 0.32 & 0.04 & 0.32 & 0.04 & -0.04 \\
\hline COMORB & -0.53 & 0.04 & -0.52 & 0.04 & -0.13 & -0.37 & 0.04 & -0.33 & 0.04 & -0.10 \\
\hline \multicolumn{11}{|l|}{ TKA } \\
\hline AGE1 & 0.27 & 0.04 & 0.28 & 0.04 & 0.10 & 0.27 & 0.04 & 0.24 & 0.04 & -0.11 \\
\hline AGE2 & 0.33 & 0.05 & 0.28 & 0.04 & -0.09 & 0.22 & 0.04 & 0.19 & 0.04 & -0.19 \\
\hline BMI1 & 0.20 & 0.06 & 0.15 & 0.06 & -0.15 & 0.12 & 0.06 & 0.13 & 0.06 & 0.07 \\
\hline BMI2 & -0.15 & 0.04 & -0.15 & 0.04 & 0.12 & -0.29 & 0.04 & -0.27 & 0.04 & -0.10 \\
\hline SEX & 0.30 & 0.04 & 0.30 & 0.03 & 0.09 & 0.24 & 0.03 & 0.22 & 0.03 & -0.12 \\
\hline COMORB & -0.50 & 0.04 & -0.49 & 0.03 & 0.06 & -0.37 & 0.03 & -0.32 & 0.03 & -0.13 \\
\hline
\end{tabular}

$\mathrm{AGE} 1=0$ if age $\leq 60$ and 1 otherwise; $\mathrm{AGE} 2=0$ if age $\leq 70$ and 1 otherwise; $\mathrm{BMI} 1=0$ if $\mathrm{BMI} \leq 25.0$ and 1 otherwise); $\mathrm{BMI}=0$ if $\mathrm{BMI} \leq 30.0$ and 1 otherwise; COMORB $=0$ if $<2$ comorbid conditions and 1 otherwise; EST Estimate, SE Standard error, $d$ Relative difference in standardized estimates between DIF model and No-DIF models; Boldface font is used to denote statistically significant estimates at $a=0.05$

post-surgery improvements [46]. The responses given by patients on the SF-12 items have some consistency with previous research, which has shown, for example, that older patients are more likely to report problems with moderate activities and climbing several flights of stairs $[47,48]$.

Our findings suggest that multimorbidity is not only a source of DIF but also had the largest contribution to the DIF model for the PH sub-scale in the relative importance analysis. Other recent studies have shown a strong association between SF-12 PH sub-scale scores and multimorbidity [49], although this covariate has not been explored for its effect in DIF analyses. At the same time, the differences in estimates of the effect of comorbidity on the $\mathrm{MH}$ and $\mathrm{PH}$ latent variables between the No-DIF and DIF models were generally small.

Item M4 from the MH sub-scale and item P1 from the $\mathrm{PH}$ sub-scale were associated with the largest contributions to the final DIF models. Adjustment for DIF did not change the direction of the association between the
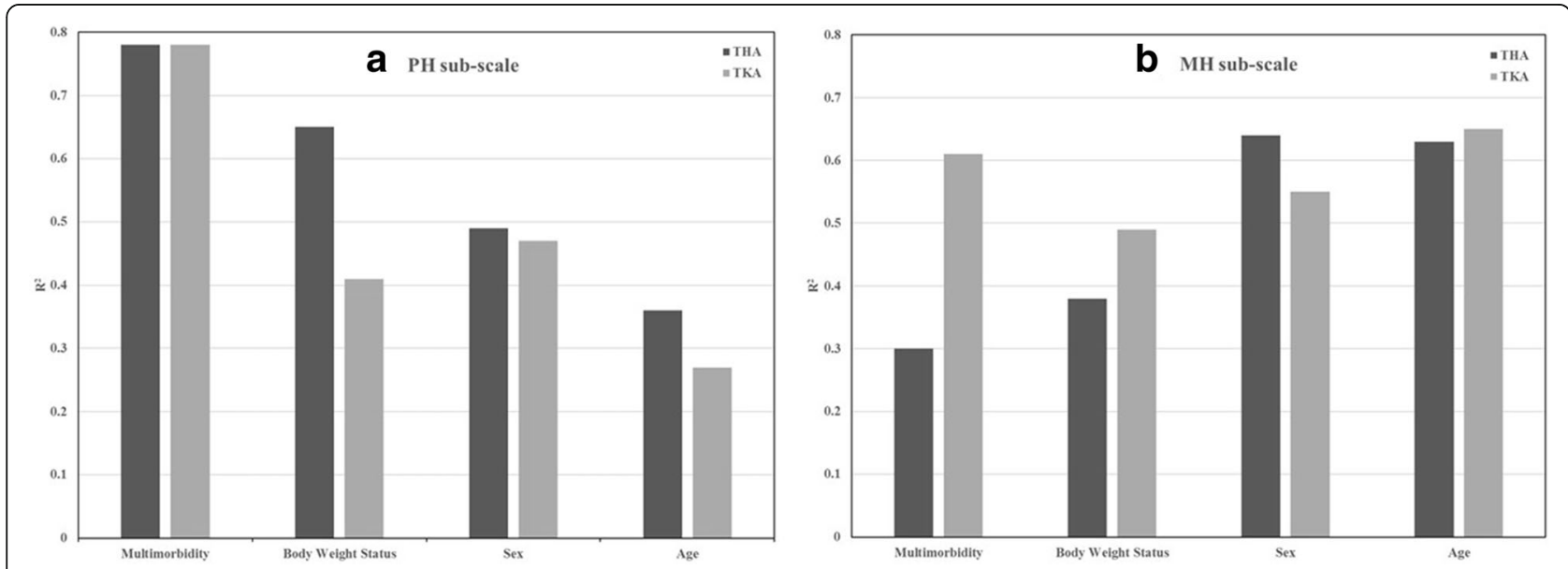

Fig. 2 Importance of the covariates in the final DIF models. a Importance analysis for the PH sub-scale. $\mathbf{b}$ Importance analysis for the $\mathrm{MH}$ sub-scale 

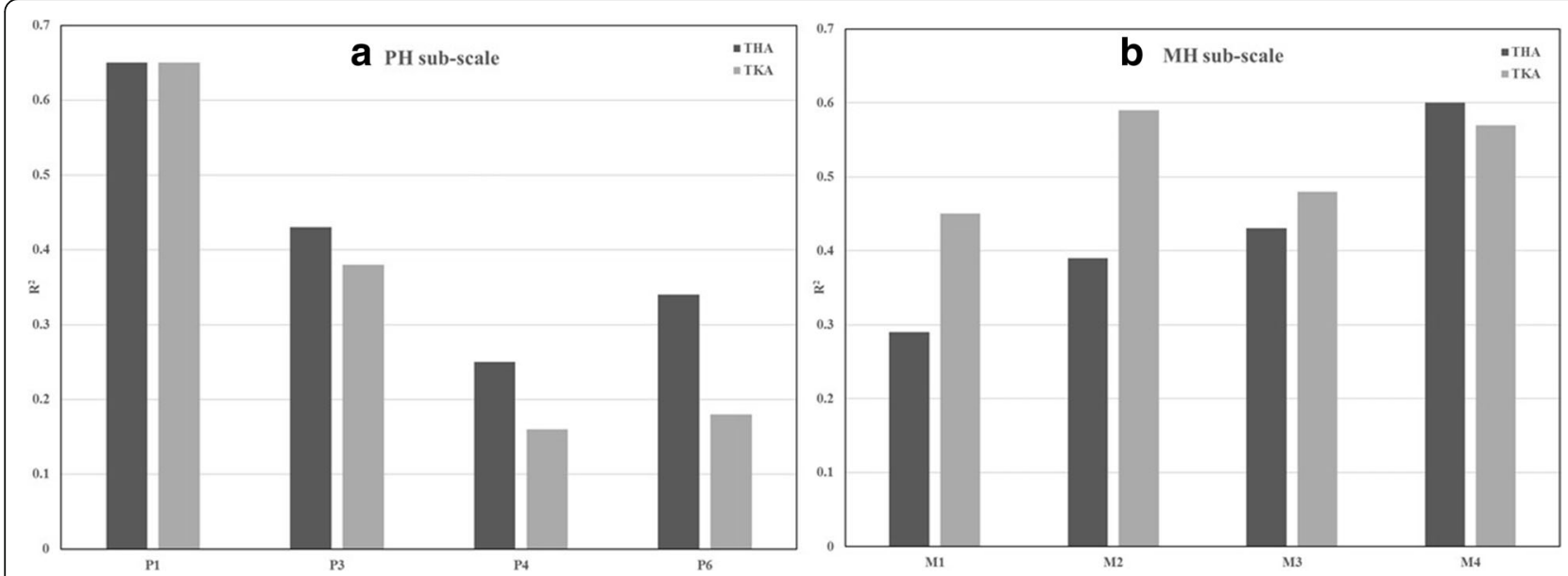

Fig. 3 Importance of the items in the final DIF models. a Importance of the PH sub-scale items. $\mathbf{b}$ Importance of the MH sub-scale items

covariates and the $\mathrm{PH}$ and $\mathrm{MH}$ scores. This result was consistent with other findings in the literature for the SF-12 and also for the SF-36 $[9,14]$.

While this study investigated DIF in a population for which PROMs are of significant value for assessing surgical outcomes, further research is warranted. Since DIF may change from pre-surgery to post-surgery occasions, future studies might explore response shift [50], a change in an individual's values, internal standards, and conceptualization of QOL over time, in joint replacement populations. Research conducted to date [51-53] has identified the presence of response shift in patients undergoing total knee replacement. As well, we only tested for uniform DIF in $\mathrm{MH}$ and $\mathrm{PH}$. The MIMIC model cannot easily be used to investigate the presence of non-uniform DIF, which involves testing interactions between covariates and latent variables on the item responses. Specification of interaction terms assumes normally distributed covariates [32]. Thus, there is opportunity for opportunities to investigate new approaches to test for non-uniform DIF in MIMIC models. Finally, the generalizability of the study findings regarding the measurement model fit to the data and presence of DIF should be explored in other joint replacement populations.

\section{Conclusions}

In summary, this study suggests the existence of DIF in population-based SF-12 data for joint replacement patients. $\mathrm{PH}$ and $\mathrm{MH}$ sub-scale scores may not be comparable across sub-groups defined by demographic and health status variables without considering the effects of DIF. Moreover, this study has provided evidence that having more than one chronic condition may be a source of DIF; multimorbidity should therefore be explored further in studies about DIF in other populations. At the same time, associations between the latent construct and the covariates revealed generally small differences between the DIF and no-DIF models, indicating that the effect of DIF on the latent construct was not substantial in either THA or TKA patients.

DIF should be given routine consideration in the analysis of PROMs because it can impact the interpretation of group differences. Measurement equivalence is essential to ensure accurate assessments of patient health; inaccurate assessment can result in incorrect estimates of the magnitude of group differences and can impact on clinical decision making about the effectiveness of interventions, such as THA and TKA, on patient's perceptions of their own health.

There are a few methods to address the presence of DIF in PROMs data, although no method is recognized as the optimal solution [54]. Removing DIF items from the SF-12 is likely to effect the validity and accuracy of this measure. Replacing DIF items with equivalent items that do not exhibit DIF is conditional on having a resource of known DIF-free items. Examining items for DIF prior to conducting analyses on the SF-12 and adjusting for DIF before comparing sub-groups may be a reasonable solution, although it can also affect the comparability of scores across populations. Sensitivity analyses, in which analyses of PROMs are conducted after accounting for DIF and then not accounting for DIF, is a feasible approach for researchers to adopt in practice.

\section{Additional files}

Additional file 1: Figure S1. Baseline model for the SF-12 mental health sub-scale. Figure S2. Baseline model for the SF-12 physical health sub-scale. (PDF $100 \mathrm{~kb}$ )

Additional file 2: Table S1. Total effects of covariates on the SF-12 mental health sub-scale items for differential item functioning (DIF) and No-DIF models, 
stratified by type of joint replacement. Table S2. Total effects of covariates on the SF-12 physical health sub-scale items for differential item functioning (DIF) and No-DIF models, stratified by type of joint replacement. (PDF $189 \mathrm{~kb}$ )

\section{Abbreviations}

BMI: Body mass index; COMORB: Comorbidity; DIF: Differential item functioning; HRQoL: Health-related quality of life; MH: Mental health; PH: Physical health; PROM: Patient-reported outcome measure; THA: Total hip arthroplasty; TKA: Total knee arthroplasty

\section{Acknowledgements}

Access to the data was provided by the Winnipeg Regional Health Authority. The results and conclusions are those of the authors and no official endorsement by the data providers is intended or should be inferred.

\section{Authors' contributions}

$I Y, O A$, and LZ conducted the analysis. LML, EB, RS, TTS, and IY conceived the study and prepared the analysis plan. IY and LML prepared the draft manuscript. All authors reviewed and approved the final version of the manuscript.

\section{Funding}

Funding for this study was provided by the Canadian Institutes of Health Research (grant \# MOP-142404). LML was supported by a Research Chair from Research Manitoba during the period of the study. RS is supported by a Tier 2 Canada Research Chair in Patient-Reported Outcomes.

\section{Availability of data and materials}

Data used in this article were derived from administrative health data as a secondary source. The data were provided under specific data sharing agreements only for the approved use. The original source data are not owned by the researchers and as such cannot be provided to a public repository. The original data source and approval for use has been noted in the acknowledgments of the article. Where necessary and with appropriate approvals, source data specific to this article or project may be reviewed with the consent of the original data providers, along with the required privacy and ethical review bodies.

\section{Ethics approval and consent to participate}

This study received ethical approval from the University of Manitoba Health Research Ethics Board. Consent was not received from study participants; this was a retrospective population-based cohort study that used secondary data and therefore obtaining consent was not practicable.

\section{Consent for publication}

Not applicable.

\section{Competing interests}

The authors declare that they have no competing interests.

\section{Author details}

'Department of Mathematics and Statistics, University of Ottawa, Ottawa, ON Canada. ${ }^{2}$ Department of Community Health Sciences, University of Manitoba, S113-750 Bannatyne Avenue, Winnipeg, MB R3E OW3, Canada. ${ }^{3}$ Department of Surgery, University of Manitoba, Winnipeg, MB, Canada. ${ }^{4}$ School of Nursing, Trinity Western University, Langley, BC, Canada. ${ }^{5}$ Department of Community Health Sciences, University of Calgary, Calgary, AB, Canada.

Received: 6 September 2018 Accepted: 27 May 2019

Published online: 02 July 2019

\section{References}

1. Maradit Kremers H, Larson DR, Crowson CS, Kremers WK, Washington RE, Steiner CA, et al. Prevalence of total hip and knee replacement in the United States. J Bone Joint Surg Am. 2015;97(17):1386-97.

2. Slover J, Zuckerman JD. Increasing use of total knee replacement and revision surgery. JAMA. 2012;308(12):1266-8.

3. Ethgen O, Bruyere O, Richy F, Dardennes C, Reginster JY. Health-related quality of life in total hip and total knee arthroplasty. A qualitative and systematic review of the literature. J Bone Joint Surg Am. 2004;86-a(5):963-74.
4. da Silva RR, Santos AA, de Sampaio Carvalho Junior J, Matos MA. Quality of life after total knee arthroplasty: systematic review. Rev Bras Ortop. 2014;49(5):520-7.

5. Rolfson O, Wissig S, van Maasakkers L, Stowell C, Ackerman I, Ayers D, et al. Defining an international standard set of outcome measures for patients with hip or knee osteoarthritis: consensus of the international consortium for health outcomes measurement hip and knee osteoarthritis working group. Arthritis Care Res (Hoboken). 2016;68(11):1631-9.

6. Rolfson O, Bohm E, Franklin P, Lyman S, Denissen G, Dawson J, et al. Patient-reported outcome measures in arthroplasty registries report of the patient-reported outcome measures working group of the International Society of Arthroplasty Registries part II. Recommendations for selection, administration, and analysis. Acta Orthop. 2016;87(Suppl 1):9-23.

7. Rolfson O, Eresian Chenok K, Bohm E, Lubbeke A, Denissen G, Dunn J, et al. Patient-reported outcome measures in arthroplasty registries. Acta Orthop Suppl. 2016;87(Suppl 1):3-8.

8. Sawatzky R, Chan EKH, Zumbo BD, Ahmed S, Bartlett SJ, Bingham CO, et al. Montreal accord on patient-reported outcomes (PROs) use series, paper 7: modern perspectives of measurement validation emphasize justification of inferences based on patient reported outcome scores. J Clin Epidemiol. 2017;89:154-9.

9. Lix LM, Wu X, Hopman W, Mayo N, Sajobi TT, Liu J, et al. Differential item functioning in the SF-36 physical functioning and mental health sub-scales: a population-based investigation in the Canadian multicentre osteoporosis study. PLoS One. 2016;11(3):e0151519.

10. Salyers MP, Bosworth HB, Swanson JW, Lamb-Pagone J, Osher FC. Reliability and validity of the SF-12 health survey among people with severe mental illness. Med Care. 2000;38(11):1141-50.

11. Wu X, Sawatzky R, Hopman W, Mayo N, Sajobi TT, Liu J, et al. Latent variable mixture models to test for differential item functioning: a population-based analysis. Health Qual Life Outcomes. 2017;15(1):102.

12. Bjorner JB, Kreiner S, Ware JE, Damsgaard MT, Bech P. Differential item functioning in the Danish translation of the SF-36. J Clin Epidemiol. 1998;51(11):1189-202.

13. Kwon JY, Sawatzky R. Examining gender-related differential item functioning of the veterans Rand 12-item health survey. Qual Life Res. 2017;26(10):2877-83.

14. Fleishman JA, Lawrence WF. Demographic variation in SF-12 scores: true differences or differential item functioning? Med Care. 2003;41(7 Suppl):lii75-iii86.

15. Bourion-Bedes $\mathrm{S}$, Schwan R, Laprevote $\mathrm{V}$, Bedes A, Bonnet JL, Baumann C. Differential item functioning (DIF) of SF-12 and Q-LES-QSF items among French substance users. Health Qual Life Outcomes. 2015:13:172.

16. Hamilton CB, Maly MR, Giffin JR, Clark JM, Speechley M, Petrella RJ, et al. Validation of the questionnaire to identify knee symptoms (QulKS) using Rasch analysis. Health Qual Life Outcomes. 2015;13:157.

17. Hermsen LA, Terwee CB, Leone SS, van der Zwaard B, Smalbrugge M, Dekker J, et al. Social participation in older adults with joint pain and comorbidity: testing the measurement properties of the Dutch Keele assessment of participation. BMJ Open. 2013;3(8):e003181.

18. Singh J, Politis A, Loucks L, Hedden DR, Bohm ER. Trends in revision hip and knee arthroplasty observations after implementation of a regional joint replacement registry. Can J Surg. 2016;59(5):304-10.

19. Dawson J, Fitzpatrick R, Carr A, Murray D. Questionnaire on the perceptions of patients about total hip replacement. J Bone Joint Surg Br. 1996;78(2):185-90.

20. Dawson J, Fitzpatrick R, Murray D, Carr A. Questionnaire on the perceptions of patients about total knee replacement. J Bone Joint Surg Br. 1998:80(1):63-9.

21. Ware J Jr, Kosinski M, Keller SD. A 12-item short-form health survey: construction of scales and preliminary tests of reliability and validity. Med Care. 1996;34(3):220-33.

22. Maurischat $C$, Herschbach $P$, Peters $A$, Bullinger M. Factorial validity of the Short Form 12 (SF-12) in patients with diabetes mellitus. Psychol Sci Q. 2008:50:7-20.

23. Chum A, Skosireva A, Tobon J, Hwang S. Construct validity of the SF-12v2 for the homeless population with mental illness: an instrument to measure self-reported mental and physical health. PLoS One. 2016;11(3):e0148856.

24. Fortin M, Bravo G, Hudon C, Vanasse A, Lapointe L. Prevalence of multimorbidity among adults seen in family practice. Ann Fam Med. 2005;3:223-8. 
25. Garrow JS, Webster J. Quetelet's index (W/H2) as a measure of fatness. Int J Obes. 1985;9(2):147-53.

26. Wohlfahrt-Veje C, Tinggaard J, Winther K, Mouritsen A, Hagen CP, Mieritz MG, et al. Body fat throughout childhood in 2647 healthy Danish children: agreement of BMI, waist circumference, skinfolds with dual X-ray absorptiometry. Eur J Clin Nutr. 2014;68(6):664-70.

27. Swaminathan $\mathrm{H}$, Rogers $\mathrm{HJ}$. Detecting differential item functioning using logistic regression procedures. J Educ Meas. 1990;27(4):361-70.

28. Orlando Edelen MO, Thissen D, Teresi JA, Kleinman M, Ocepek-Welikson $K$. Identification of differential item functioning using item response theory and the likelihood-based model comparison approach. Application to the mini-mental state examination. Med Care. 2006;44(11 Suppl 3):S134-42.

29. Langer MM, Hill CD, Thissen D, Burwinkle TM, Varni JW, DeWalt DA. Item response theory detected differential item functioning between healthy and ill children in quality-of-life measures. J Clin Epidemiol. 2008;61(3):268-76.

30. Shih C-L, Wang W-C. Differential item functioning detection using the multiple indicators, multiple causes method with a pure short anchor. Appl Psychol Meas. 2009;33(3):184-99.

31. Woods CM, Oltmanns TF, Turkheimer E. Illustration of MIMIC-model DIF testing with the schedule for nonadaptive and adaptive personality. J Psychopathol Behav Assess. 2009;31(4):320-30.

32. Woods CM, Grimm KJ. Testing for nonuniform differential item functioning with multiple indicator multiple cause models. Appl Psychol Meas. 2011;35(5):339-61.

33. Okonkwo OC, Roth DL, Pulley L, Howard G. Confirmatory factor analysis of the validity of the SF-12 for persons with and without a history of stroke. Qual Life Res. 2010;19(9):1323-31.

34. Muthen B, Asparouhov T, Muthen L. Latent variable analysis with categorical outcomes: multiple-group and growth modeling in Mplus. Mplus Web Notes: No 4 Version 5; 2002.

35. Wang W-C, Shih C-L. MIMIC methods for assessing differential item functioning in polytomous items. Appl Psychol Meas. 2010;34(3):166-80.

36. Lord FM. Applications of item response theory to practical testing problems. Hillsdale: Erlbaum Associates; 1980.

37. Cook KF, Kallen MA, Amtmann D. Having a fit: impact of number of items and distribution of data on traditional criteria for assessing IRT's unidimensionality assumption. Qual Life Res. 2009;18(4):447-60.

38. Hu L-t, Bentler PM. Cutoff criteria for fit indexes in covariance structure analysis: conventional criteria versus new alternatives. Struct Equ Model. 1999;6(1):1-55

39. Browne MW, Cudeck R. Alternative ways of assessing model fit. Sociol Methods Res. 1992;21:230-58.

40. Woods CM. Empirical selection of anchors for tests of differential item functioning. Appl Psychol Meas. 2009;33(1):42-57.

41. Cohen J. Statistical power analysis for the behavioral sciences (2nd ed.). Hillsdale: Erlbaum; 1988.

42. Budescu DV. Dominance analysis: a new approach to the problem of relative importance of predictors in multiple regression. Psychol Bull. 1993; 114(3):542-51.

43. Nagelkerke NJ. A note on a general definition of the coefficient of determination. Biometrika. 1991;78:691-2.

44. Tonidandel S, LeBreton JM. Determining the relative importance of predictors in logistic regression: an extension of relative weight analysis. Organ Res Methods. 2010;13(4):767-81.

45. Tonidandel S, LeBreton JM. Relative importance analysis: a useful supplement to regression analysis. J Bus Psychol. 2011;26(1):1-9.

46. Chiu HC, Mau LW, Hsu YC, Chang JK. Postoperative 6-month and 1-year evaluation of health-related quality of life in total hip replacement patients. J Formosan Med Assoc. 2001;100(7):461-5.

47. Yu YF, Yu AP, Ahn J. Investigating differential item functioning by chronic diseases in the SF-36 health survey: a latent trait analysis using MIMIC models. Med Care. 2007:45(9):851-9.

48. Perkins AJ, Stump TE, Monahan PO, McHorney CA. Assessment of differential item functioning for demographic comparisons in the MOS SF36 health survey. Qual Life Res. 2006;15(3):331-48.

49. Gonzalez-Chica DA, Hill CL, Gill TK, Hay P, Haag D, Stocks N. Individual diseases or clustering of health conditions? Association between multiple chronic diseases and health-related quality of life in adults. Health Qual Life Outcomes. 2017;15(1):244.
50. Sprangers MA, Schwartz CE. Integrating response shift into health-related quality of life research: a theoretical model. Soc Sci Med. 1999:48(11):1507-15.

51. Razmjou H, Yee A, Ford M, Finkelstein JA. Response shift in outcome assessment in patients undergoing total knee arthroplasty. J Bone Joint Surg Am. 2006;88(12):2590-5.

52. Zhang XH, Li SC, Xie F, Lo NN, Yang KY, Yeo SJ, et al. An exploratory study of response shift in health-related quality of life and utility assessment among patients with osteoarthritis undergoing total knee replacement surgery in a tertiary hospital in Singapore. Value Health. 2012;15(Suppl 1):S72-8.

53. Razmjou H, Schwartz CE, Yee A, Finkelstein JA. Traditional assessment of health outcome following total knee arthroplasty was confounded by response shift phenomenon. J Clin Epidemiol. 2009;62(1):91-6.

54. Teresi JA, Fleishman JA. Differential item functioning and health assessment Qual Life Res. 2007;16(Suppl 1):33-42.

\section{Publisher's Note}

Springer Nature remains neutral with regard to jurisdictional claims in published maps and institutional affiliations.
Ready to submit your research? Choose BMC and benefit from:

- fast, convenient online submission

- thorough peer review by experienced researchers in your field

- rapid publication on acceptance

- support for research data, including large and complex data types

- gold Open Access which fosters wider collaboration and increased citations

- maximum visibility for your research: over $100 \mathrm{M}$ website views per year

At $\mathrm{BMC}$, research is always in progress.

Learn more biomedcentral.com/submissions 